\title{
Nonlinear and Nonparametric Dynamical Methods in Economics and Finance
}

\section{Md Gazi Salah Uddin}

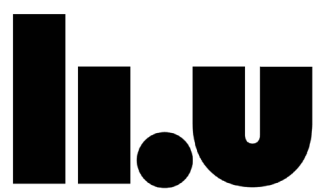

LINKÖPING UNIVERSITY

Linköping Studies in Arts and Science No. 680

Linköpings Universitet, Department of Management and Engineering SE-581 83 Linköping, Sweden

Linköping 2016 


\section{Linköping studies in Arts and Science - No. 680}

At the Faculty of Arts and Science at Linköping University, research and doctoral studies are carried out within broad problem areas. Research is organized in interdisciplinary research environments and doctoral studies mainly in graduate schools. Jointly, they publish the series Linköping Studies in Arts and Science. This thesis comes from Economics at the Department of Management and Engineering.

Distributed by:

Department of Management and Engineering

Linköping University

SE-581 83 Linköping, Sweden

Md Gazi Salah Uddin

Nonlinear and Nonparametric Dynamical Methods in Economics and Finance

Edition 1:1

ISBN: 978-91-7685-768-7

ISSN 0282-9800

(C) G. S. Uddin

Department of Management and Engineering 2016

(Cover designed by Gazi Salah Uddin)

Printed by: LiU-Tryck 2016 
To My Parents 



\begin{abstract}
The objectives of the thesis - which comprises six parts - can be summarized in i) implementing linear and nonlinear/nonparametric approaches toward detecting, measuring and analyzing the nature and directionality of causal relationships in financial markets, ii) elaborating on modern topics in financial investment analysis, iii) probing into the role of commodity futures in constructing optimal portfolios as well as $i v$ ) investigating growth dynamics via aggregated and disaggregated indices.
\end{abstract}

The first paper named "Analyzing causal interactions between sectoral equity returns and commodity futures returns in the aftermath of the global financial crisis: The case of the US and EU equity returns", aims to explore and compare the dependence and co-movement structure between commodity and various asset classes' returns including the USA and EU stock markets via the use of linear and nonlinear causality testing in a comparative context with the additional adjustment for cointegration and conditional heteroscedasticity. The findings provide important implications for optimal asset allocation and portfolio diversification with respect to various market conditions, namely both in "good" and "bad" (crisis) times.

The second paper is entitled "On the time scale behaviour of Equity-Commodity links: Implications for Portfolio Management", and has been published in the Journal of International Financial Markets, Institutions and Money (2016). The study is co-authored with Professors S. Bekiros, D.K. Nguyen, and B. Sjö. It develops a holistic framework for the investigation of the multi-horizon and intra-frequency causal directionalities of various asset classes, by means of multi-resolution analysis. The results verify the assumption that financial markets exhibit time-varying co-movement patterns, which are fundamentally important in $a$ ) generating profitable trading strategies according to different investor horizon expectations and $b$ ) decoding the financialization mechanism across various asset classes.

The third paper entitled "Business Cycle (de) Synchronization in the aftermath of the Global Financial Crisis: Implications for the Euro Area", was published at Studies in Nonlinear Dynamics and Econometrics (2015) and is co-authored with S. Bekiros, D.K Nguyen and B. Sjö. In this work, the scaledependent time-varying (de)synchronization effects between the Eurozone and the broad Euro area business cycles are revealed, before and after the global financial crisis. The results, which point towards an increased observed co-movement during the crisis period for the Euro area, could be catalytic for the introduction of a more efficient monetary policy by EU institutions and in particular by the European Central Bank.

In the fourth paper, "Do financial stress and policy uncertainty have an impact on the energy and metals markets? A quantile regression approach", which was published in the International Review of Economics and Finance (2016) and co-authored with J.C. Reboredo, the financial and policy uncertainty is investigated in relation to the price dynamics of energy and metal commodity futures' markets. This work lead to the analysis of the asymmetric interrelationships with respect to changes in the perceptions of various risk measures, covering various periods, i.e., "normal" vs. "turbulent" such as upward or downward market episodes.

The fifth paper, co-authored with P. Andreasson, S. Bekiros and D.K. Nguyen, is entitled "The impact of speculation and economic uncertainty on commodity markets", and is published in the International Review of Financial Analysis (2016). This paper attempts a novel methodological approach to measuring speculation in commodity markets, in particular whether market speculation drives agricultural commodity prices or vice-versa. The assessment of the empirical analysis demonstrates that agricultural prices are not affected by speculation.

Finally, the sixth paper "Energy and Output Dynamics in Bangladesh", co-authored with B.P. Paul, was published in Energy Economics (2011) and explores the relationship between energy utilization and economic growth in Bangladesh. Specifically, it deals with the important issue of whether energy consumption can be reduced without affecting economic growth while at the same time implicitly may lead to poverty reduction. The findings substantiate the fact that $a$ ) energy usage has become more efficient in recent times, as well as indicate that $b$ ) fluctuations in energy consumption did not have a significant impact on economic output.

Keywords: Commodity markets, Nonlinear causality testing, Dependence structure, Business cycles, Timescale analysis, Growth dynamics, Portfolio management 



\section{Acknowledgements}

After obtaining a Master degree in Economics and Finance from the University of Skövde (Sweden) in 2005, I went back to my home country, Bangladesh, to teach economics and finance courses and to prepare myself for a Ph.D. in Economics and an academic career as my long-term goal. In the meantime, I benefited much from advanced training in economics at Carleton University (Canada). Then, ultimately in 2012, I was admitted to Linköping University (Sweden) as a Ph.D. candidate in economics, where I have had the opportunity to further develop my research interests in applied time series econometrics with interfaces to finance, energy economics and macroeconomic dynamics.

The Ph.D. program in Linköping (with a strong emphasis on core courses in microeconomics, macroeconomics, and quantitative methods) has provided me with a very good theoretical foundation. Furthermore, additional rigorous courses in econometrics and finance have allowed me to deepen my understanding of the methods for empirical analysis of advanced problems in financial economics.

Sweden is a multi-cultural country and a leader when it comes to offering research facilities to international scholars. As a Researcher, I am looking forward to contributing to the economic development of both Sweden and my home country Bangladesh. I believe that my study program in Linköping University will eventually enable me to accomplish this goal.

I would like to express my sincere thanks to my supervisor, Associate Professor Bo Sjö, for his advice and encouragement over the last several years, which started during my Master's degree and has continued throughout my Ph.D. studies at Linköping University. He has taken me through my thesis achievements in a step by step manner. He has also provided advice and guidelines for my scientific insights on the subjects I have been dealing with. His training has enabled me to improve my quantitative and qualitative skills in writing scientific articles. I will always remain grateful to him.

I want to express my gratitude to Professor Duc Khuong Nguyen, not only for his tremendous academic and research support, but also for providing me with the opportunities to attend several international conferences and research visits at the IPAG Business School in France. He has been a mentor to me, who guided me in refining my research topics, and trained me in writing scientific research articles in financial economics. 
I am also appreciative for the help and guidance offered by Professor Stelios Bekiros, especially for sharing his econometrics and spectral analysis expertise, and for acting as a dedicated examiner of my work. He also mentored me in developing econometrics skills and its application in economics and finance. Moreover, I am grateful to him for all the comments, which I received at different seminars and international conferences.

I have been awarded numerous financial scholarships and grants for participating in Ph.D. courses and training, including from Swedish House of Finance, Stockholm School of Economics; CREATES, Aarhus University, Denmark; Nordic Finance Network, Copenhagen Business School, Denmark; Carleton University, Canada and IPAG Business School, France. I have benefited from the lectures and advice from Timo Teravirta, Ramazan Gençay, Mariassunta Giannetti, Ba M. Chu and Fanny S. Demers. I thank Richard J. Sweeney for his valuable editorial guidance and wellthought comments on my work. Furthermore, I would like to thank Tapan Mahmud and Rachel Ellis, who assisted me in organizing and proof-reading my work.

I would like to extend my gratitude to all faculty members and staff at the division of economics at Linköping University who helped me in various ways by providing inspiring discussions and arguments. My special appreciation goes to Professor Ali Ahmed, whose knowledge and expertise helped me in numerous ways. I will forever be thankful to him for his invaluable help, moral support and career advice. Special thanks go to Brian M Lucy, Juan Carlos Reboredo, Gören Hägg, Henrik Nehler, Chiraz Labidi, Clas Wihlborg, Maher Asal, H. A. Ahmed. Phouphet Kyophilavong, Christina Svensson, Paul Nystedt, Tomas Conlon, Nasim Syed, Roger Bandick and Joakim Persson.

The journey towards completing this thesis started before I arrived at Linköping University. I would like to extend my gratitude to my former teachers, namely, Professor Abdulnasser HatemiJ, Biru Paul, Gour Govinda Gosami, Mia Mikic, AH Chowdhury, Lokman Uzun and Ahmed Nasim Sydee.

Most importantly, I would like to express my deepest gratitude to my parents: Great Freedom Fighter of Bangladesh-my father-Md Ulfat Ali and my mother Sumsun Naher (along with my sibling Ayesha Akhter) for their constant support and inspiration. Finally, I am grateful to my wife Dr. Mourin Hussian and son Mohammad Gazi Naheyan for their valuable sacrifices and love, which have stimulated me to pursue my Ph.D. training until its completion, in a blissful manner. Linköping, April 2016

\section{Md Gazi Salah Uddin}




\section{Introduction}

The global financial crisis and recent volatility in food and commodity prices have increased the interest in the relation between the co-movement of prices in financial markets. This thesis looks at some aspects of the relation between stock prices on the one hand and commodity prices including assets such as agricultural goods and energy on the other.

Modern portfolio theory explains how investors can improve their portfolios by selecting assets for which prices are relatively uncorrelated with each other. The key to successful investment strategies is to understand correlations among assets and to use this knowledge in constructing portfolios. At the basic text book level, correlation is a simple and constant statistical measure. In real life, correlation structures might change over time and over measured time scales, over business cycles, and with different macroeconomic risk factors.

Since the early 1990s there has been a growing financialization of commodity markets, meaning that new financial instruments based on commodities have been created and incorporated in portfolios. Furthermore, during the last decade prices of commodities such as metals, oil, gold and agricultural goods have fluctuated widely. Against this background it is natural to ask if assets such as commodities are uncorrelated with other assets' prices or not. If commodities assets turn out to be quite uncorrelated with other assets, then they can help to stabilize financial portfolios and thereby help to steer real assets into more productive use.

Since the beginning of this century, agricultural commodities have mostly displayed a positive price pattern. For example, Corn went from $\$ 1.97$ per bushel in January 2005 to $\$ 4.04$ per bushel in January 2007, while the Oats and Soybeans both peaked during the crisis period in 2008. The increase in Wheat prices could also serve as evidence that demand factors were the most important drivers of the food crisis in 2007-2008. According to the U.S. Department of Agriculture (2009), 75-80 million people went hungry during this food crisis. Facts like these have raised the attention of the global world for food security (Headey, 2013).

Overall, commodities have acquired a growing relevance for both investment funds and retail investors' portfolios in recent decades. And trading in commodity-related financial assets has become increasingly sophisticated (Henderson et al., 2015). It is also evident that the statistical and econometrical methods used to measure correlations in commodity markets have been inadequate. The global financial meltdown of 2007-2008 had a severe impact on the real economy and on what were considered to be well-diversified portfolios immune to recessions. It is now an established fact that the tendency for extreme increases in dependence during recessions results in increased tail risk in financial portfolios. Therefore, practitioners stressed the need for a more cautious management of financial risks.

A large numbers of studies have suggested that the returns of financial assets are asymmetric, nonlinear, and time-varying (Longin and Solnik, 2001; Ang and Chen, 2002; Zimmer, 2012; Bekiros, 2014). Moreover, the co-movements among asset classes indicate statistically significant dependence structures (in both directionality and nature) (Bekiros, 2014; Uddin, 2015).

Whether the correlation across commodities and other financial markets has increased after the outbreak of the financial crisis is a matter for debate. Bekiros et al., (2016) conclude that equity and commodity markets exhibit time-varying co-movement patterns and behave differently across investment horizons in the aftermath of the global financial crisis. In practice, market participants have diverse trading objectives which may be affected by institutional changes, business cycle phases and major turmoil in economic and financial markets. The trading behavior on these markets could differ between short-term and longterm investors. In this situation, the effect of time scales on asset correlation can be used to find new optimal diversification strategies for short-term and long-term investors. 
Another aspect of the time-varying nature of the dependence structure across financial markets are how they react to different types of shocks. Thus, we can look for the sources of dynamic behaviour in asset price correlation by analyzing how different risk factors play different roles for high (positive) and low (negative) returns (Bernanke, 1983; Bloom, 2009; Pastor and Veronesi, 2012). However, recent research indicates that uncertainty relating to stock market conditions is not of crucial importance for commodity futures prices (Reboredo and Uddin, 2016) which appear to be driven by alternative macroeconomic fundamentals to a greater extent than other asset classes (Gorton and Rouwenhorst, 2006; Roll; 2013; Andreasson et al., 2016)). These findings have interesting implications for how to create more well-diversified and stable financial portfolios.

Finally, there is a discussion over the causal directions between energy consumption and total economic output. Specifically, the discussion deals with the important issue of whether energy consumption can be reduced without affecting economic growth, while at the same time reducing poverty. The relationship between energy consumption and output is still ambiguous in the existing literature. Paul and Uddin, (2011) find that, for Bangladesh, energy usage has become more efficient in recent times. In addition, they indicate that fluctuations in energy consumption did not have a significant impact on economic output. This implies that the energy conservation and efficiency can be relevant in policymaking for developing countries for ensuring sustainable economic development.

It turns out from the above discussions that the fluctuation in commodity prices has important global economic consequences and may also affect equity markets and investors' strategies. Therefore, a detailed analysis of the dynamics of commodity prices, equity prices and business cycles and their interrelations is worthwhile, in particular in the aftermath of the global financial crisis and the recent turbulent times. To this end, this thesis consists of six papers in which I explore different aspects of the dependence and causality between equity markets, commodity markets and macroeconomic factors. The (de)synchronization of the Euro area business cycles (Bekiros et al., 2015) as well as the role of economic uncertainty and speculation are also investigated.

In the first paper, I comprehensively explore the nature and direction of causality between commodity markets and other various asset classes. I investigate in particular the nonlinear and asymmetric nature of the information. The evidence of industry-specific results leads to the conclusion that distinct industries may react differently vis-à-vis the commodity markets. It also provides invaluable information for stock investors who seek diversification benefits from commodity investments, as they can design optimal portfolios and hedging strategies based on the detected interrelations.

Papers $2 \& 3$ cover various recent aspects of spectral analysis, namely multi-scale dynamics in asset prices and scale-dependent time-varying business cycle (de)synchronization. On the one hand, the results of the second paper confirm the existence of time-varying dependence patterns between equity and commodity markets and illustrate the importance of the time scale in implementing profitable trading strategies and understanding the financialization mechanism across various asset classes. On the other hand, the third paper documents the time-varying and scale-dependent business cycles (de)synchronization effects between the Eurozone and the broad Euro zone area. Finally, papers 4, 5 \& 6 examine the time-varying linear and nonlinear dynamics of commodity price movements and dependence structure. The first two articles explore the impact of different types of uncertainty, including economic, financial and policy uncertainty as well as speculation on commodity markets. The sixth article examines energy and output dynamics in Bangladesh. 


\title{
2. Summary of the thesis ${ }^{1}$
}

\section{1 Nonlinear Causality}

Paper I: Analyzing the causal interactions between sectoral equity returns and commodity futures returns in the aftermath the global financial crisis: the case of the U.S. and the EU equity markets

\begin{abstract}
This study focuses on analyzing the causal interactions between sectoral equity returns and commodity futures returns in the United States and European market using an analytical framework constituting linear and non-linear causality tests aftermath of the global financial crisis. This study attempts to explore the dependence structure and direction of causality after controlling for co-integration and conditional heteroscedasticity in the data. This paper contributes in particular, to the existing literature in several dimensions. First, this study is extensively tested and validated on a micro level comprehensive assessment of the dependence structure and the direction of causality within the investigated markets. Second, this study used a causality-based co-movement approach to detecting the causal dependence between commodity and sectoral equity returns with its flexible specifications via the linear, non-linear and asymmetric causality tests. Third, this study conducts important analyses of portfolio management by estimating several specifications in portfolios in different subsamples. The empirical results for the evidence of causality as well as nonlinearity and asymmetric causality play an important role in the investigated markets especially in oil and yellow metals group of commodities. Furthermore, it provides helpful information for stock investors who are seeking benefits from diversified commodity investment, since they can design optimal portfolios and hedging strategies by approaching those results. Additionally, following the sub-sample analysis, it is noted that, the commodities also play an important role for international portfolio diversification among these markets. These synergistic causality results offer an important implication for optimal asset allocation and portfolio diversification.
\end{abstract}

\subsection{Spectral Analysis}

Paper II: On the time scale behavior of Equity-Commodity links: Implications for Portfolio Management. Journal of International Financial Markets, Institutions and Money, Vol. 41, pp.30-46, 2016 (with S. Bekiros, D.K. Nguyen, and B. Sjö)

Abstract: We investigate the time-scale relationships between US equity and commodity markets. The empirical evidence from the risk-return profitability analysis based on the wavelet coherence measure shows that equity and commodity markets exhibit time-varying co-movement patterns, and behave differently across investment horizons. Our study contributes to the literature in three major aspects. Firstly, we assess how commodity and equity returns in the United States co-move both over time and across different investment horizons. Secondly, we verify the emerged co-movement by detecting the causality effects between commodity and equity returns via the frequency domain causality test. Finally, we show the importance of time scale analysis for portfolio management by estimating and comparing the portfolio performance in multi-scale horizon. We find evidence of timefrequency causality between the two investigated markets. These results further uncover that the performance of diversified portfolios including both equity and commodity assets differs importantly across diverse investment horizons. Our results can have important implications for optimal asset allocation and portfolio diversification. In this article, I contributed the literature review, data construction, summary statistics, empirical analysis and portfolio performance.

\footnotetext{
${ }^{1}$ Extended abstract
} 
Paper III: Business Cycle (de) Synchronization in the Aftermath of the Global Financial Crisis: Implications for the Euro Area. Studies in Nonlinear Dynamics and Econometrics, Vol.19 (5), pp.609-624, 2015 (with S. Bekiros, D.K Nguyen and B. Sjö)

\begin{abstract}
The introduction of the Euro currency was a game-changing event intended to induce convergence of Eurozone business cycles on the basis of greater monetary and fiscal integration. The benefit of participating in a common currency area exceeds the cost of losing autonomy in national monetary policy only in cases of cycle co-movement. However, synchronization was put back mainly due to country-specific differences and asymmetries in terms of trade and fiscal policies that became profound at the outset of the global financial crisis. As opposed to previous studies that are mostly based on linear correlation or causality modeling, we utilize the cross-wavelet coherence measure to detect and identify the scaledependent time-varying (de)synchronization effects amongst Eurozone and the broad Euro area business cycles before and after the financial crisis. Our results suggest that the enforcement of an active monetary policy by the ECB during crisis periods could provide an effective stabilization instrument for the entire Euro area. However, as dynamic patterns in the lead-lag relationships of the European economies are revealed, (de)synchronization varies across different frequency bands and time horizons. In this article, my role was to prepare the data construction, summary statistics, results and discussions.
\end{abstract}

\title{
2.3 Time-varying Nonlinear Dependence
}

Paper IV: Do financial stress and policy uncertainty have an impact on the energy and metals markets? A quantile regression approach. International Review of Economics and Finance, Vol. 43, pp.284-298, 2016 (with J.C. Reboredo)

Abstract: This paper examines the impact of financial and policy uncertainty on the price dynamics of energy (crude oil, heating oil and gas) and metal (gold, silver, copper, platinum and palladium) commodity futures in the USA. This study analyses how financial stress (as defined by the VIX and the STLFSI) and policy uncertainty (as defined by the US monthly Economic Policy Uncertainty Index, EPUI) shape return distributions for the most tradable energy (crude oil, heating oil and gas) and metal (gold, silver, copper, platinum and palladium) commodities in the USA. To that end, we used a quantile regression (QR) approach as it allows examination of co-movement and causality in specific market circumstances, including bearish (lower quantile), bullish (upper quantile) and normal (intermediate quantile) markets. By examining those effects via $\mathrm{QR}$, we add to the existing literature on the commodity-stock market nexus in three ways. First, we measure how dependence and causality between commodity futures prices and financial and policy uncertainty have changed in different market circumstances, a fact that has implications for investors in terms of risk management and the predictability of commodity prices. Second, we account for the impact of the global financial crisis on commodity returns quantiles. Third, controlling for the effect of the general stock market returns index and interest rates, we provide evidence of no co-movement and no causality between commodity prices and financial stress or between commodity prices and policy uncertainty. However, we did find evidence that financial stress has (negative) causality effects on the intermediate and upper quantiles of the commodity returns distribution but without evidence of co-movement. Our results indicate that general stock market uncertainty conditions are not so crucial in determining commodity futures prices. In this article, my role was to prepare the Introduction, data construction, summary statistics, results and discussions. 
Paper V: The impact of speculation and economic uncertainty on commodity markets. International Review of Financial Analysis, Vol 43, pp.115-127, 2016 (with P. Andreasson, S. Bekiros and D.K. Nguyen)

\begin{abstract}
We examine the interactions between commodity futures returns and five driving factors (financial speculation, exchange rate, stock market dynamics, implied volatility for the US equity market, and economic policy uncertainty). Nonlinear causality tests are implemented after controlling for co-integration and conditional heteroscedasticity in the data over the period May 1990 - April 2014. This work contributes to the growing literature in commodity markets interdependence detection with respect to five potential drivers. We utilize a commodity market speculation index represented by the Working's $T$ Index, two macroeconomic factors; a trade weighted Major Currency Index and S\&P 500 representing US stock market performance, the CBOE-VIX and the Economic Policy Uncertainty index in order to capture the extent of economic and political uncertainty. The co-movement of commodities vis-à-vis FX and equity markets or volatility indices (VIX) is not particularly well investigated. This might result in under- or over-stating the role of commodities in portfolio asset management; for instance, speculation could possibly be a major driving factor of commodity prices. Overall, the new evidence found in this paper can be utilized for policy and investment decision-making. In this article, my role was to prepare the Introduction, data construction, summary statistics, results and discussions.
\end{abstract}

Paper VI: Energy and Output Dynamics in Bangladesh. Energy Economics, Vol. 33 (3), pp.480-487, 2011 (with B.P. Paul)

Abstract: The discussion over the link between energy consumption and output has been widespread, particularly since the global oil shocks of the early 1970s. Bangladesh has always been noted for its acute power shortage. Bangladesh's energy infrastructure is small, insufficient, and per capita energy use in Bangladesh is one of the lowest in the world. Only 32 percent of Bangladesh's population has access to electricity, with a per capita availability of 185 kWh per annum. The economy of Bangladesh, having spectacular output growth and rising energy demand as well as energy efficiency in recent decades, can be an ideal case for examining energy-output dynamics. We find that while fluctuations in energy consumption do not affect output fluctuations, movements in output inversely affects movements in energy use. The results of Granger causality tests in this respect are consistent with those of innovative accounting that includes variance decompositions and impulse responses. Autoregressive distributed lag models also suggest a role of output in Bangladesh's energy use. Hence, the findings of this study have policy implications for other developing nations where measures for energy conservation and efficiency can be relevant in policymaking. In this article, my role was to prepare the Introduction, data construction, summary statistics, results and discussions. 


\section{References}

Andreasson, P., Bekiros, S., Nguyen, D. K., \& Uddin, G. S. (2016). Impact of speculation and economic uncertainty on commodity markets. International Review of Financial Analysis, 43, $115-127$.

Ang, A., \& Chen, J. (2002). Asymmetric correlations of equity portfolios. Journal of financial Economics, 63(3), 443-494.

Bekiros, S. (2014). Exchange Rates and Fundamentals: Co-Movement, Long-Run Relationships and Short-Run Dynamics. Journal of Banking and Finance, 39, 117-134.

Bekiros, S., Nguyen, D. K., Uddin, G. S., \& Sjö, B. (2015). Business cycle (de) synchronization in the aftermath of the global financial crisis: implications for the Euro area. Studies in Nonlinear Dynamics \& Econometrics, 19(5), 609-624.

Bekiros, S., Nguyen, D. K., Uddin, G. S., \& Sjö, B. (2016). On the time scale behavior of equitycommodity links: Implications for portfolio management. Journal of International Financial Markets, Institutions and Money. 41, 30-46.

Bernanke, B. S., (1983). Irreversibility, uncertainty, and cyclical investment. Quarterly Journal of Economics 98, 85-106.

Bloom, N. (2009). The impact of uncertainty shocks. Econometrical 77 (3), 623-685.

Gorton, G., and Rouwenhorst, K. G. (2006). Facts and Fantasies about Commodity Futures.

Financial Analysts Journal 62(2), 47-68.

Headey, D. D. (2013). The impact of the global food crisis on self-assessed food security. The World Bank Economic Review, 27(1), 1-27.

Henderson, B. J., Pearson, N. D., \& Wang, L. (2015). New evidence on the financialization of commodity markets. Review of Financial Studies, 28(5), 1285-1311.

Longin, F., \& Solnik, B. (2001). Extreme correlation of international equity markets. The journal of Finance, 56(2), 649-676.

Pastor, L., Veronesi, P. (2012). Uncertainty about government policy and stock prices. Journal of Finance 67, 1219-1264.

Paul, B. P., \& Uddin, G. S. (2011). Energy and output dynamics in Bangladesh. Energy Economics, 33(3), 480-487.

Reboredo, J. C., \& Uddin, G. S. (2016). Do financial stress and policy uncertainty have an impact on the energy and metals markets? A quantile regression approach. International Review of Economics \& Finance. 43, 284-298.

Roll, R., (2013). Volatility, correlation, and diversification in a multi-factor world. Journal of Portfolio Management 39, 11-18.

Uddin, G.S. (2015). Analyzing the causal interactions between sectoral equity returns and commodity futures returns in the aftermath the global financial crisis: the case of the U.S. and the EU equity markets. Commodity market Conference, Oslo, Norway.

USDA. (2009). Food Security Assessment, 2008-09. United States Department of Agriculture (USDA), Economic Research Service (ERS), Washington, DC.

Zimmer, D. M., (2012). The role of copulas in the housing crisis. Review of Economics and Statistics, 94, 607-620. 


\section{Table of Contents}

Paper 1: Analyzing the causal interactions between sectoral equity returns and commodity futures returns in the aftermath the global financial crisis: the case of the U.S. and the EU equity markets

1.1 Abstract 1

$\begin{array}{lr}1.2 \text { Introduction } & 2\end{array}$

$\begin{array}{ll}\text { 2.1 Data and preliminary analysis } & 8\end{array}$

2.2 Architecture of the econometric methodology 12

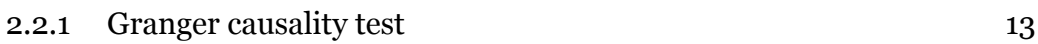

2.2.2 Granger causality in leveraged bootstrap test $\quad 14$

$\begin{array}{ll}\text { 2.2.3 Nonlinear causality test } & 15\end{array}$

$\begin{array}{ll}\text { 2.2.4 Asymmetric causality test } & 16\end{array}$

$\begin{array}{ll}2.3 \text { Results and discussions } & 17\end{array}$

2.3.1 Granger causality test $\quad 17$

$\begin{array}{ll}\text { 2.3.2 Nonlinear causality test } & 21\end{array}$

$\begin{array}{lll}2.3 \cdot 3 & \text { Asymmetric causality test } & 27\end{array}$

2.4 Portfolio performance 33

2.4.1 Risk adjusted undiversified portfolio performance 35

$\begin{array}{ll}\text { 2.4.2 Risk adjusted diversified portfolio performance } & 36\end{array}$

$\begin{array}{ll}2.5 \text { Conclusions } & 39\end{array}$

2.6 References $\quad 42$

Figure 1 Logarthim prices of equity and commodity futures 47

Figure 2 Returns of equity market and commodity futures 49

Table 1 Descriptive statistics $\quad 51$

Table 2 The correlations: equity and commodity futures returns 53

Table 3 Unit root tests $\quad 55$

Table 4 Linear causality tests $\quad 57$

$\begin{array}{ll}\text { Table } 5 \text { Non-linear causality tests } & 61\end{array}$

Table 6 Asymmetric causality tests 64

Table 7 Risk adjusted undiversified portfolio performance 68

$\begin{array}{ll}\text { Table } 8 \text { Risk adjusted diversified portfolio performance } & 70\end{array}$

\section{Appendix}

$\begin{array}{ll}\text { A Lag structure and cointegrating vector } & 79\end{array}$

B GARCH-types of models $\quad 80$ 


\section{List of Published Papers}

Paper 2: On the time scale behavior of Equity-Commodity links: Implications for Portfolio Management. Journal of International Financial Markets, Institutions and Money, Vol. 41, pp.30-46, 2016 (with S. Bekiros, D.K. Nguyen, and B. Sjö)

Paper 3: Business Cycle (de) Synchronization in the Aftermath of the Global Financial Crisis: Implications for the Euro Area. Studies in Nonlinear Dynamics and Econometrics, Vol.19 (5), pp.609-624, 2015 (with S. Bekiros, D.K Nguyen, and B. Sjö)

Paper 4: Do financial stress and policy uncertainty have an impact on the energy and metals markets? a quantile regression approach. International Review of Economics and Finance, Vol. 43, pp.284-298, 2016 (with J.C. Reboredo)

Paper 5: The impact of speculation and economic uncertainty on commodity markets. International Review of Financial Analysis, Vol 43, pp.115-127, 2016 (with P. Andreasson, S. Bekiros, and D.K. Nguyen)

Paper 6: Energy and Output Dynamics in Bangladesh. Energy Economics, Vol. 33 (3), pp.480-487, 2011 (with B. P. Paul) 


\section{Papers}

The articles associated with this thesis have been removed for copyright reasons. For more details about these see:

http://urn.kb.se/resolve?urn=urn:nbn:se:liu:diva-127340 